\title{
La primera etapa del IEHC (Instituto de Estudios Hispánicos de Canarias) y el impulso progresista en las exposiciones de mujeres artistas desde 1953 a 1965
}

\author{
Ángeles Alemán Gómez ${ }^{1}$
}

Recibido: 1 de marzo de 2018 / Aceptado: 20 de agosto de 2018

Resumen. Existe una línea frágil pero visible que rompe la monotonía y la oscuridad de las décadas de 1950 y 1960 en Canarias. En un momento de la historia en que todo era silencioso temor, en que la moral más conservadora y restrictiva se había apoderado de la sociedad, varias mujeres artistas decidieron batallar por su arte y lograron llevar a cabo una serie de exposiciones, artículos y amistad que culminaron en una exposición pionera de mujeres artistas, titulada simplemente Las Doce.

Para enmarcar esta historia, protagonizada por varias mujeres de distinta procedencia pero ligadas especialmente por la artista e intelectual surrealista Maud Bonneaud- Westerdahl, debemos proceder primero a situar el espacio en el que tuvo lugar, el Instituto de Estudios Hispánicos de Canarias (IEHC) que dio cobijo al inacabado proyecto del Museo de Arte Contemporáneo Eduardo Westerdahl en el Puerto de la Cruz.

La búsqueda realizada a través de archivos públicos y privados, además de múltiples lecturas y entrevistas, ha sido esencial para ir encajando las piezas de esta historia que presentamos pues a pesar de haber sido opacada por la historiografía tradicional, termina ahora saliendo a la luz y ayudando a comprender mejor la importancia de estas mujeres.

Palabras clave: Mujeres artistas; Exposiciones; Surrealismo; Maud Boneaud-Westerdahl; Las Doce; Instituto de Estudios Hispánicos de Canarias.

\section{[en] The first stage of the IEHC (Institute of Hispanic Studies of the Canary Islands) and the progresist impulse in female artists exhibitions from 1953 to 1965}

\begin{abstract}
There is a fragile but visible line that breaks the monotony and the darkness of the 50s and 60s in Canary Islands. At this dark moment when everything was silenced, in which more conservative and restrictive morality had seized up in society, several female artists decided to battle it out for their Art and managed to make several exhibitions and articles that culminated in an exhibition of women artists, which was titled Las Doce.

To frame this story, protagonized by several women from different backgrounds, but especially linked by the artist and surrealist intellectual Maud Bonneaud - Westerdahl, we must proceed to explain the place where it took place, the Institute of Estudios Hispánicos de Canarias (IEHC) which gave shelter to the unfinished project of the Museum of Contemporary Art Eduardo Westerdahl in Puerto de la Cruz, Tenerife.

The search carried out through the several Public and restricted Archives, as well as multiple readings and interviews, have been essential to link the different parts of this story that we present, despite it
\end{abstract}

1 Universidad de Las Palmas de Gran Canaria. Departamento de Arte, Ciudad y Territorio angeles.aleman@ulpgc.es

Código ORCID: 0000-0002-2614-4083 
having been overshadowed by the traditional History of Art, coming to light and helping to better understand the importance of these women who made it possible.

Keywords: Women artists; exhibitions; Surrealism; Maud Boneaud-Westerdahl; Las Doce; Instituto de Estudios Hispánicos de Canarias.

Sumario. Introducción. / El Instituto de Estudios Hispánicos del Puerto de la Cruz y Eduardo Westerdahl (1953-1965). / Maud Bonneaud y la relación con el Surrealismo. / Sitio Litre: Encuentros con Eileen Agar. / Las exposiciones de mujeres artistas en el IEHC (1953-1965). / Conclusiones.

Cómo citar: Alemán Gómez, Á. (2018) La primera etapa del IEHC (Instituto de Estudios Hispánicos de Canarias) y el impulso progresista en las exposiciones de mujeres artistas desde 1953 a 1965 , en Anales de Historia del Arte $\mathrm{n}^{\circ} 28$ (2018), 383-394.

\section{Introducción}

En el Archivo Eileen Agar de la Tate Gallery (Londres) existen varias fotografías tomadas en Sitio Litre, Puerto de la Cruz, Tenerife, en las que aparecen junto a la artista británica dos mujeres esenciales para comprender la revitalización del arte canario en estos años: la poeta surrealista Valentine Penrose y la artista surrealista, además de crítica de arte y gestora cultural, Maud Bonneaud- Westerdahl.

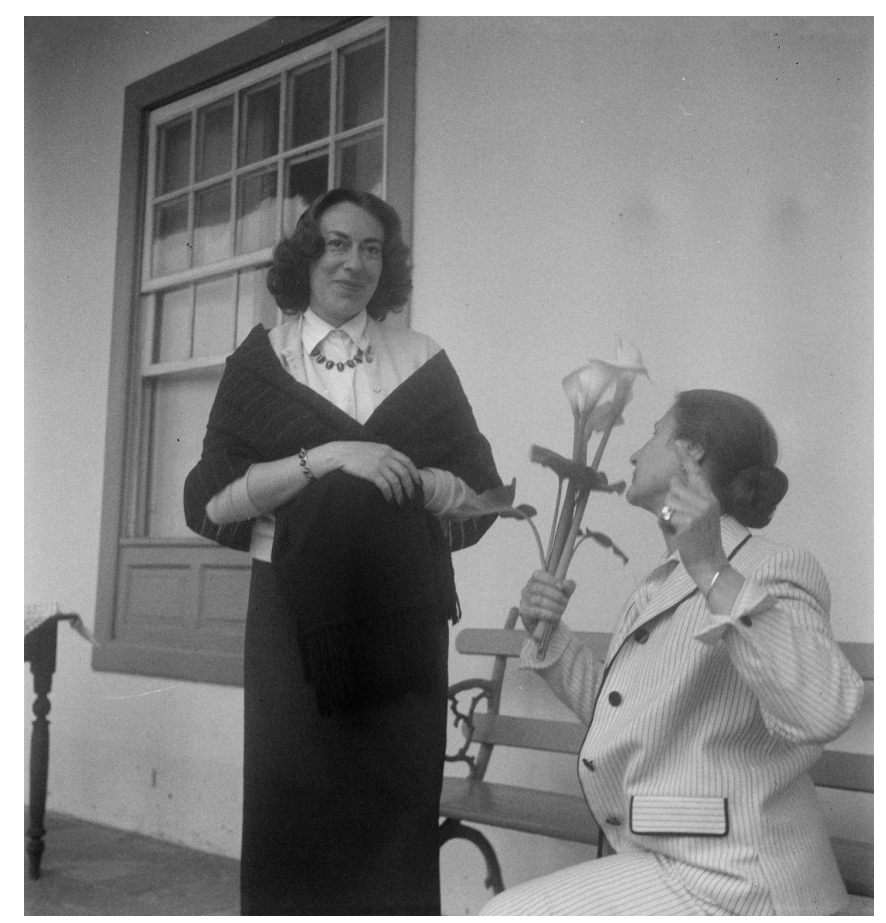

Fig. 1. Autor: Eileen Agar . Valentine Penrose y Maud Westerdahl en Sitio Litre, Puerto de la Cruz, Tenerife, 1957. Tate Archive, Referencia TGA 8927/8/67,

Copyright Tate, http: //www.tate.org.uk 
La importancia de estas fotografías, tomadas en varias etapas-1955, 1957, 1959es que muestran la estrecha relación que existió entre estas tres mujeres y su relación con Tenerife, en especial Maud Bonneaud, pues vivió en Tenerife desde su matrimonio con Eduardo Westerdahl hasta su marcha a Madrid en 1985.

Maud Bonneaud es esencial para comprender el impulso feminista -ella se describía a sí misma como surrealista cartesiana además de feminista- del IEHC durante la etapa que estudiamos, pues es su presencia la que explica la variedad y calidad de exposiciones realizadas por mujeres artistas -incluyendo ella misma- durante los años en que Eduardo Westerdahl pudo organizar la programación expositiva de este centro. A partir de 1965, y debido a un cambio radical en la directiva del IEHC, Eduardo Westerdahl fue apartado del mismo, aunque su labor como crítico de arte, así como el trabajo de Maud Bonneaud como artista, crítica de arte y gestora cultural, continuaron en otros ámbitos.

Por su parte, Maud Bonneaud tuvo amistad con las figuras más importantes del Arte europeo del siglo XX: amiga de Breton y de Picasso, había vivido en el París ocupado y contraído ahí matrimonio con Oscar Domínguez, artista surrealista canario afincado en París, divorciándose de él en 1955 para contraer matrimonio con Eduardo Westerdahl. Maud Bonneaud fue una artista de gran personalidad y trabajó el esmalte como medio técnico. Colaboró de manera puntual con Christian Dior en 1947, en 1950 vendió uno de sus cuadros al Museo de Arles, y parte de sus obras se encuentran en la Galería Dina Vierny. De hecho Maud Bonneaud sería esencial para consolidar el proyecto del MACEW y para establecer también una relación fructífera con las y los artistas de su época. A principios de la década de 1960, además de su labor dinamizadora en torno al MACEW, inició una serie de exposiciones en el Circulo de Bellas Artes de Tenerife, que desembocan en la creación del grupo de Las Doce, el primer grupo de mujeres artistas que se consolida en Canarias y que desarrolla una labor de forma independiente.

\section{EI Instituto de Estudios Hispánicos del Puerto de la Cruz y Eduardo Westerdahl (1953-1965)}

Para entender la presencia femenina en el IEHC, y en general la programación moderna y progresista de los años que estudiamos, debemos comprender la importancia que Eduardo Westerdahl tuvo como organizador en esta etapa.

Eduardo Westerdahl, a quien su nacionalidad sueca le había salvado de ser perseguido por sus ideas progresistas, tenía a sus espaldas ya una consolidada trayectoria como crítico de arte. Antes de la Guerra Civil, había sido director de la revista Gaceta de Arte (1932-35) y organizador de la II Exposición Internacional Surrealista celebrada en Tenerife (1935) con la asistencia de André Breton, Jacqueline Lamba y Benjamín Peret. Tras la Guerra Civil y pese a las dificultades para poner en marcha proyectos de carácter vanguardista, continuó con su activa militancia a favor del arte contemporáneo. Prudente y bien aconsejado por amigos como Isidoro Luz Carpenter, el entonces alcalde del Puerto de la Cruz que creó el IEHC, se mantuvo apartado de Santa Cruz, en la que el peligro de ser denunciado era mucho mayor. De hecho logró mantener, en los primeros años de posguerra, un silencio discreto que unido a su nacionalidad extranjera le permitieron vivir sin sobresaltos y gracias a la invitación de Mathias Goeritz, pudo retomar su actividad en pro del arte moderno, asistiendo de manera anual a las 
reuniones celebradas entre 1948 y 1952 en Santillana del Mar, de las que surgirían el Grupo Altamira y el I Congreso de Arte Abstracto de Santander en 1953.

Tal y como podemos constatar en la actas de estas reuniones, Eduardo Westerdahl no sólo expresaba sus planteamientos teóricos sobre "el arte nuevo" sino que además explicaba cómo estaba trabajando para crear, con la base de su colección privada, un Museo de Arte Contemporáneo en el Puerto de la Cruz. Su colección, que contaba entonces con algunas obras significativas del arte moderno ${ }^{3}$, encontró a partir de 1953 acomodo provisional en el IEHC mientras, año tras año, vería como su sueño de crear el Museo de Arte Contemporáneo Eduardo Westerdahl, que contaba además con el proyecto del arquitecto italiano Alberto Sartoris, se iba diluyendo en la burocracia para caer, durante muchos años, en el olvido ${ }^{4}$.

\section{Maud Bonneaud y la relación con el Surrealismo}

Maud Bonneaud y Eduardo Westerdahl se conocieron en París en 1952. Este encuentro es esencial para comprender el apoyo incondicional que Eduardo Westerdahl encontró en ella a partir de entonces, en su lucha conjunta por la modernidad, y en la apertura que supuso para él conocer a una artista surrealista y de sólidas convicciones feministas. Maud escribió acerca de este encuentro: "Conocí a Eduardo Westerdahl en París en 1952 a través de su gran amigo Oscar Domínguez, de quien estaba yo separada en términos de máxima elegancia, estimación y amistad mutua".

Maud Bonneaud fue invitada por Westerdahl a Tenerife. A una primera visita en 1953 siguió otra en 1954. Durante ésta, Maud Bonneaud expuso sus esmaltes en el Casino de Tenerife y en Las Palmas de Gran Canaria, donde fue entrevistada por María Teresa Prats de Laplace para la revista Mujeres en la Isla ${ }^{6}$. En esta entrevista, publicada en dos números consecutivos, la artista francesa hablaba de su experiencia con los esmaltes:

A decir verdad, en un trabajo manual no hay "fuente de inspiración" a la cual se puede ir el artista a beber cuando tiene sed. Generalmente son la misma materia y las necesidades técnicas del trabajo las que llevan desde un camino hacia otro.

En el caso del esmalte, el metal y el fuego son dos poderosos frenos...?

Maud y Eduardo Westerdahl contrajeron matrimonio el 14 de noviembre de 1955 en Paris. Después de su boda, a la que asistieron varios de sus amigos surrealistas,

AAVV (1951): Primera semana de Arte de Santillana del Mar, Madrid: Ed. Escuela de Altamira, 114.

3 Según el Catalogo Provisional editado en 1954 y que hemos podido consultar en el archivo del IEHC, la colección constaba de 26 pinturas.

$4 \quad$ Olvido que ha sido subsanado gracia al interés y al trabajo de las personas e instituciones que hicieron posible en 2004 instalar esta colección en la Casa de la Aduana del Puerto de la Cruz, en condiciones correctas, y publicar además catálogos y monografías que ha permitido su estudio.

5 Entrevista anónima, sin fecha, archivo Hugo Westerdahl, citada en Castro, F. y Mollá, A. (2005): Eduardo y Maud Westerdahl. 2 miradas del siglo 20, Gran Canaria: CAAM, 17.

$6 \quad$ Mujeres en la Isla fue publicada desde 1953 hasta 1964 en Las Palmas de Gran Canaria. En esta revista participaron de manera directa o indirecta todas las mujeres que relacionadas con el arte o la poesía tenían presencia en la cultura canaria. Fueron 118 números en total.

$7 \quad$ Prats de Laplace, M.T. (1954). Hablando con Maud Bonneaud de arte y moda, Mujeres en la Isla, 5. 
entre ellos Valentine Penrose y Jenny y Luc Peire (que serían después sus anfitriones en Bélgica), iniciaron su viaje de novios. Después de Bélgica viajaron a Gran Bretaña- donde visitaron a Roland Penrose y Lee Miller en Fairley Farm- y más tarde visitaron a Picasso en La Californie.

\section{Sitio Litre: Encuentros con Eileen Agar}

En los años 50 fueron frecuentes los viajes de Maud y Eduardo Westerdahl a Francia y a Inglaterra. En correspondencia, algunos de sus amigos, especialmente Valentine Penrose, disfrutaron de largas temporadas en casa del matrimonio Westerdahl ${ }^{8}$. A estas visitas se unían las de los amigos alojados en Sitio Litre, especialmente y tal como hemos comentado, la artista surrealista Eileen Agar y su marido Josep Beard ${ }^{9}$.

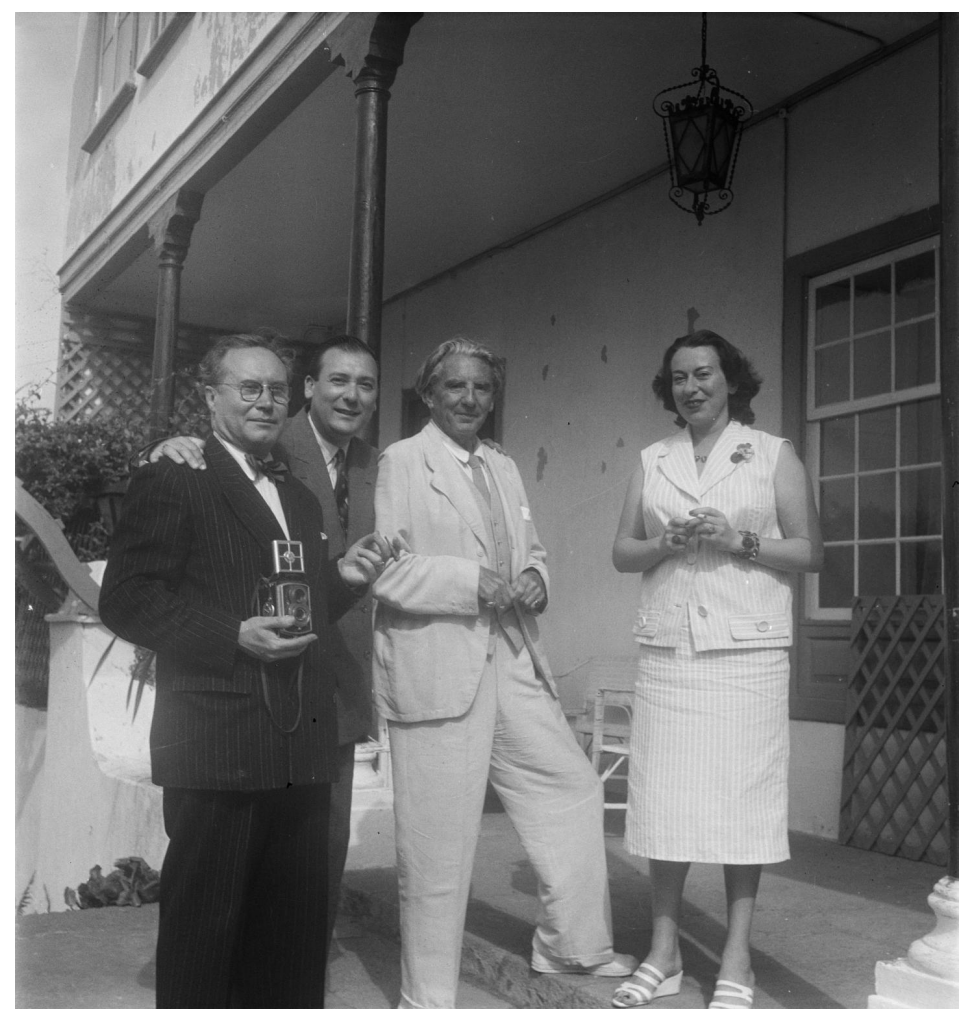

Fig.2. Autor: Eileen Agar. Joseph Bard con Eduardo y Maud Westerdahl, y Antonio Ruiz,1952-6, Sitio Litre, Puerto de la Cruz, Tenerife. Tate Archive, Referencia: TGA 8927/8/70, Copyright Tate, http: //www.tate.org.uk

8 Ver Aline Orban, S. (2014). Avis de Recherche: Valentine Penrose, oeuvre et vie d'une artiste surréaliste, Louisiana State University, LSU Digital Commons, 167 y 175. También se recogen noticias de estas visitas en otros textos; en el poema que Pedro Garcia Cabrera le dedicó a Valentine Penrose, y en el fondo fotográfico de Eileen Agar en la Tate Gallery, entre otros, así como en las notas autobiográficas de Maud Westerdahl.

9 Archivo fotográfico de Eileen Agar, Tate Gallery, Londres. 
Esta amistad mantenida a lo largo de los años, resulta muy significativa para entender la presencia de la vanguardia realizada por mujeres artistas en la programación cultural de la época y en el enriquecimiento poético y plástico del panorama insular, pues en este sentido, Valentine Penrose y Eileen Agar comparten su fascinación por la Isla, tal y como hace notar Eduardo Westerdahl en su texto sobre la exposición de la segunda en el IEHC:

La pintora Eileen Agar nos ha dado plásticamente el sueño de la isla, como hace años nos lo diera literariamente André Breton en su "Castillo Estrellado"... Con este mismo tema recuerdo haber visto recientemente para ser ilustrado por el pintor Oscar Dominguez, un manuscrito caprichoso y bellísimo de la poetisa francesa Valentine Penrose...Y así Tejina es una diosa y Anaga un rey, que unidos a Tacoronte crean su Olimpo en la arquitectura de unos versos poderosos ampliando en un vasto sueño el paraíso de unas islas entroncadas con la leyenda ${ }^{10}$.

Este artículo, que escribe con motivo de la exposición de Eileen Agar en el IEHC, supone además el reconocimiento de una figura de importancia internacional en el panorama insular, pues la exposición lleva el título completo de "Exposición de pinturas de la artista británica Eileen Agar del London Group", 26 de abril de 1956.

\section{Las exposiciones de mujeres artistas en el IEHC (1953-1965)}

En el IEHC, podemos destacar dos etapas aunque entre ellas coinciden o se alternan en ocasiones. En la primera, destacan las artistas que proceden de otros países y cuya relación con Tenerife es temporal. En la segunda podemos distinguir artistas reconocidas dentro del panorama canario y la presencia de artistas extranjeras ya instaladas o ligadas de manera más profunda a Canarias.

En los primeros años del IEHC, y posiblemente debido a la dificultad de contar con mujeres artistas canarias o establecidas de manera permanente en el territorio insular, las autoras que exponen tienen en común su procedencia nórdica.

En la colectiva Exposición de Pinturas de Artistas Suecos, del 3 al 14 de diciembre de 1953, expone por primera vez en el IEHC la artista Agda Holmsen, que mantendría una larga y fructífera relación con los Westerdahl y por ende con el IEHC. Durante este año no hay más exposiciones de mujeres artistas, pero podemos constatar en el catálogo provisional editado en 1954, las obras de cinco mujeres: Eva Varre, Linnea Poponius, Ulla Malm, Gunilla Kilhman y Carla Prina, quien tendrá una estrecha relación con el IEHC. La presencia de estas obras en el catálogo provisional es significativa, pues se trata de obras que Eduardo Westerdahl había adquirido para ser expuestas de manera permanente en su museo.

10 Westerdahl, E. (1956). Eileen Agar, La Tarde, 17 de mayo de 1956. 
Un año más tarde, el 28 de noviembre de 1955 se inaugura una exposición individual de Agda Holmsen, una de cuyas obras pasa a la colección del futuro Museo, encontrándose expuesta actualmente en la Casa de la Aduana.

En 1956, del 23 de enero al 6 de febrero, tiene lugar una exposición individual de Maila Mikkola y más tarde, en abril del mismo año, Agda Holmsen vuelve a exponer, esta vez compartiendo espacio con Acke Fornander. Es de destacar que en el folleto de sala, donde se especifican las obras expuestas, Agda presenta nueve trabajos.

La segunda etapa de esta programación está marcada por una mayor presencia femenina y, además, por mujeres que tienen una relación más estrecha con Canarias. A esta nueva etapa no es ajena la importancia de Maud Westerdahl, que actúa como "una atentico imán", en palabras de María Belén Morales, para los artistas extranjeros que vienen a Tenerife y para las artistas residentes en las Islas.

La exposición individual de Eileen Agar marca el inicio de esta nueva etapa. Tal y como ya hemos comentado, Eduardo Westerdahl da cuenta de la importancia internacional de esta artista. Gracias a la amistad de Maud Bonneaud con los Penrose, él ha podido contemplar la obra de Eileen Agar en la colección Penrose. Asimismo, es consciente del papel que había tenido esta artista en la I Exposición Surrealista celebrada en Londres en 1936. Por su parte, Eileen Agar ha encontrado en Tenerife un lugar lleno de luz y disfruta de largas estancias en la isla, hospedada en Sitio Litre junto a su marido, Joseph Beard, que colabora también en la activación cultural del IEHC impartiendo varias conferencias. De la visión que tiene Eileen Agar del paisaje de Tenerife existen varios ejemplos, entre ellos dos cuadros pertenecientes a la colección del MACEW actualmente expuestos en la Casa de la Aduana: "Bencomo" y "Desde Cornwall a Canarias". De la importancia de esta exposición dan cuenta, además del texto de Westerdahl en La Tarde, los artículos de Alfonso Padrón y de Antonio Ruiz Alvarez ambos en el periódico El Día, además del programa que se le dedica en Radio Club Tenerife.

Tras la exposición de Eileen Agar, expone Pino Ojeda, artista de Gran Canaria, cuya trayectoria como poeta estaba ya consolidada ${ }^{11}$, siendo esta exposición el descubrimiento de su faceta como artista plástica. Del 12 al 20 de enero de 1957, "Exposición pictórica de Pino Ojeda", exhibe obras en encáustica, óleo y gouache, y de las obras expuestas, tal y como se puede comprobar en el catálogo, tres han sido seleccionadas para la III Bienal de Arte Hispanoamericano de Barcelona. En un artículo publicado en La Tarde, se expresa la admiración que provoca la artista: "Pino Ojeda, la gran creadora de arte... Su alta sensibilidad moderna y su selecta formación constituyen dotes no comunes de las cuales se derivan obras sugestivas"12.

La buena acogida de la pintura de Pino Ojeda hizo que meses más tarde expusiera en el Casino de Tenerife. En esta ocasión Eduardo Westerdahl escribió un artículo sobre su pintura:

Igual que en su poesía, Pino Ojeda establece unas formas poderosas, unos colores determinados, unos cuerpos cargados de presencia, que se afirman en su fondo, cerrando el paso a toda evasión... Su capacidad poética necesitaba recurrir al lenguaje de la plástica para seguir trabajando en sus invariables sueños sólidos ${ }^{13}$.

\footnotetext{
Pino Ojeda y Chona Madera habían dado un recital de poesía en el IEHC en octubre del año anterior. Sin firma (1957). Pino Ojeda en el Instituto de Estudios Hispánicos, La Tarde, 11 de enero de 1957. Westerdahl, E. (1957). La pintura de Pino Ojeda, Tenerife: Casino de Tenerife, folleto de sala.
} 


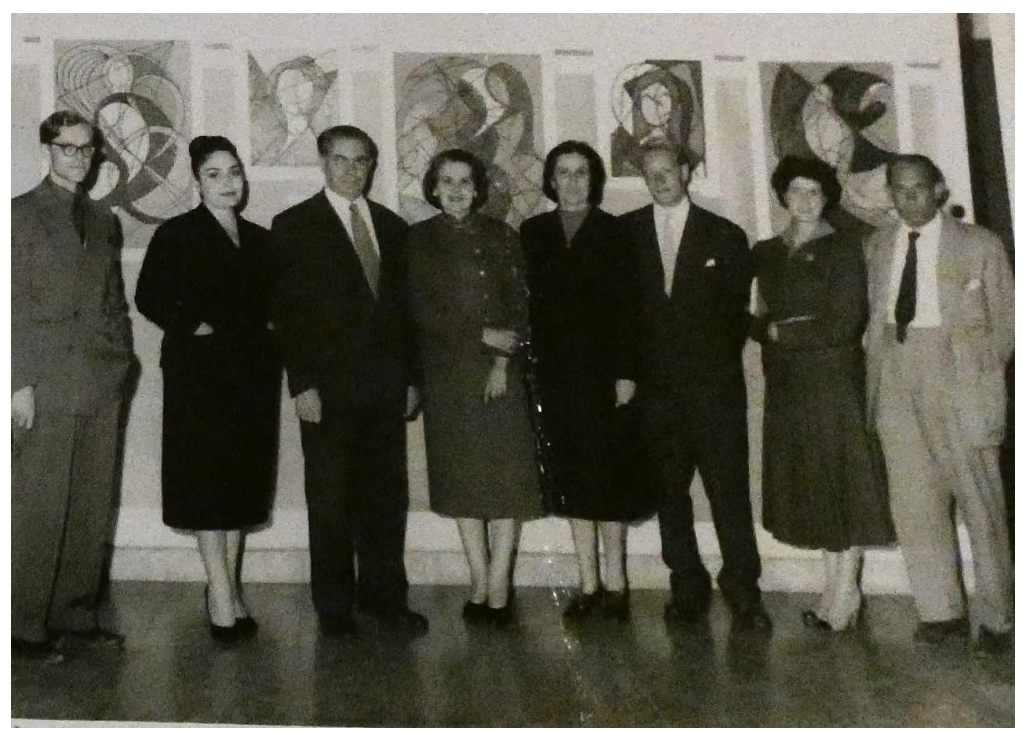

Fig. 3. Autor: anónimo, 1957. Fotografía de grupo en la inauguración de la exposición de Pino Ojeda, situada segunda por la izquierda, Tras ellos están varios de sus cuadros. Archivo del IEHC, Puerto de la Cruz, Tenerife

Tras la exposición de Pino Ojeda en el IEHC, Maud Westerdahl expone por primera vez en esta institución, aunque ya había expuesto en el Casino de Tenerife y era conocida también por sus artículos en el diario La Tarde. En esta exposición, realizada entre el 14 y el 21 de marzo de 1957, Maud Westerdahl mostraba joyas y también cuadros realizados con su peculiar técnica, esmalte mezclado con fragmentos de vidrio. La exposición titulada "Historia Natural Artificial" tenía como protagonistas formas animales inspiradas en las joyas medievales que ella conocía bien de sus visitas al Museo de Artes Decorativas de París, pero también incluía formas abstractas, como "Pequeño fuego verde", que pertenece al MACEW y actualmente se encuentra expuesto en la Casa de la Aduana.

Tras la exposición de Maud Westerdahl, Gretha Turner expuso entre el 28 de junio y el 14 de julio del mismo año. Esta artista sueca, miembro del KRO (Asociación de Artistas de Suecia), recibió una elogiosa crítica: "Su afán culmina en ansias de sublimar las forma, desrealizándolas, espiritualizándolas, desnudándolas del atuendo de la realidad para dárnoslas en lo que tienen de íntimo y de trascendente"14.

En lo que resta de año no se reseñan más exposiciones de mujeres artistas, siendo la siguiente la "Exposición de Pinturas, dibujos y y esculturas de la artista norteamericana Yela Brichta", del 5 al 18 de febrero de 1958, que cuenta con un texto de Eduardo Westerdahl en el folleto de sala, siendo ésta la primera vez que el díptico se ampliaba con un texto teórico sobre la obra expuesta. Westerdahl escribió: "Yela Brichta ha tratado los opuestos desde la conjunción de planos abstractos hasta los árboles y las casas que le rodean. Para ella cada motivo tiene su interpretación, según su estado de ánimo o su propia y responsable concepción"15.

14 Sin firma. (1957). Exposición pictórica de Gretha Turner, El Día, 2 julio 1957.

15 Westerdahl, E. (1958): Exposición de Pinturas, dibujos y esculturas de Yela Brichta, Puerto de la Cruz: IEHC. Folleto de sala. 
La presencia femenina durante 1958 es escasa y sólo en 1959 vuelve a tener un ritmo notable, con una exposición de Eva Fernández de Guigou del 30 de marzo al 10 de abril. La pintura de Eva Fernández, ya considerada por entonces una artista reconocida, recibe varias reseñas en prensa, que hacen hincapié en su manejo maestro de los pinceles. A pesar de este éxito, la siguiente exposición femenina no se programa hasta diciembre de ese año, siendo la artista Agda Holmsen la que expone. Junto a sus pinturas, y pese a no aparecer junto a ella en la portada del folleto de la muestra, se exhiben también en esta ocasión esculturas en madera de otra artista, Ulla Nygren.

La temporada más reseñable de exposiciones femeninas, tanto por la cantidad como por la calidad, se produce en 1960, aunque en algunos casos se empieza a resquebrajar la tendencia moderna y aparece una pintura de tipo tradicional que muestra las grietas de la influencia de Westerdahl, que será sustituido unos años más tarde por una dirección reaccionaria.

Empieza el año con una exposición doble de Tanja Tamvelius y Maud Westerdahl, del 25 de febrero al 10 de marzo de 1960. Las dos artistas, que colaboran en diversas ocasiones, mantienen un dialogo fluido entre los tapices y pinturas de Tanja Tamvelius y los esmaltes de Maud Westerdahl. De hecho sería Tanja Tamvelius la encargada de decorar en 1962 el edificio La Osa Mayor, propiedad de los Westerdahl, con un mural.

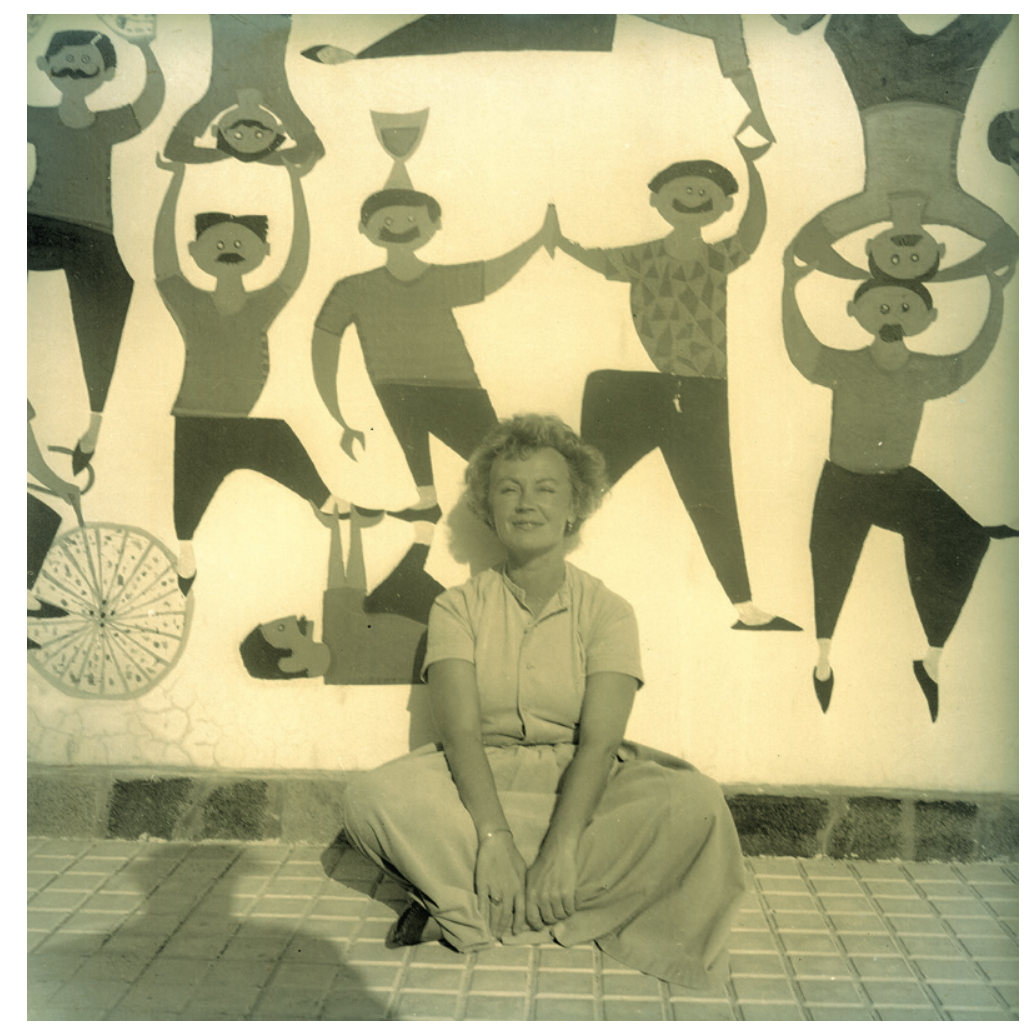

Fig. 4. Autor: Eduardo Westerdahl. Tanja Tamvelius ante el mural de La Osa Mayor, Bajamar. Fondo Westerdahl, AHTP, Gobierno de Canarias. 
En marzo de 1960, del 20 al 30, la exposición de Mary Rosario Camps muestra una pintura muy clásica de factura, que rompe con la estética de filiación vanguardista que había sido constante hasta entonces, mostrando una de las grietas a las que antes aludíamos. La influencia de Francisco Bonnín, extremadamente academicista, se hacía notar cada vez más.

Sin embargo, aún quedaban varias exposiciones programadas que expresan bien los ideales estéticos de Maud Bonneaud y Eduardo Westerdahl. La siguiente sería la exposición de María Cremaes, del 25 de abril al 4 de mayo. Más tarde, habría dos exposiciones consecutivas de artistas italianas, representativas de la modernidad que tanto defendían los Westerdahl: la de Vivi Milano, que expone del 14 al 24 de octubre, y cuya relación con el mundo artístico canario se va a intensificar con los años, y Rosetta Zingale, que expone en el IEHC desde el 25 al 30 de octubre de 1960.

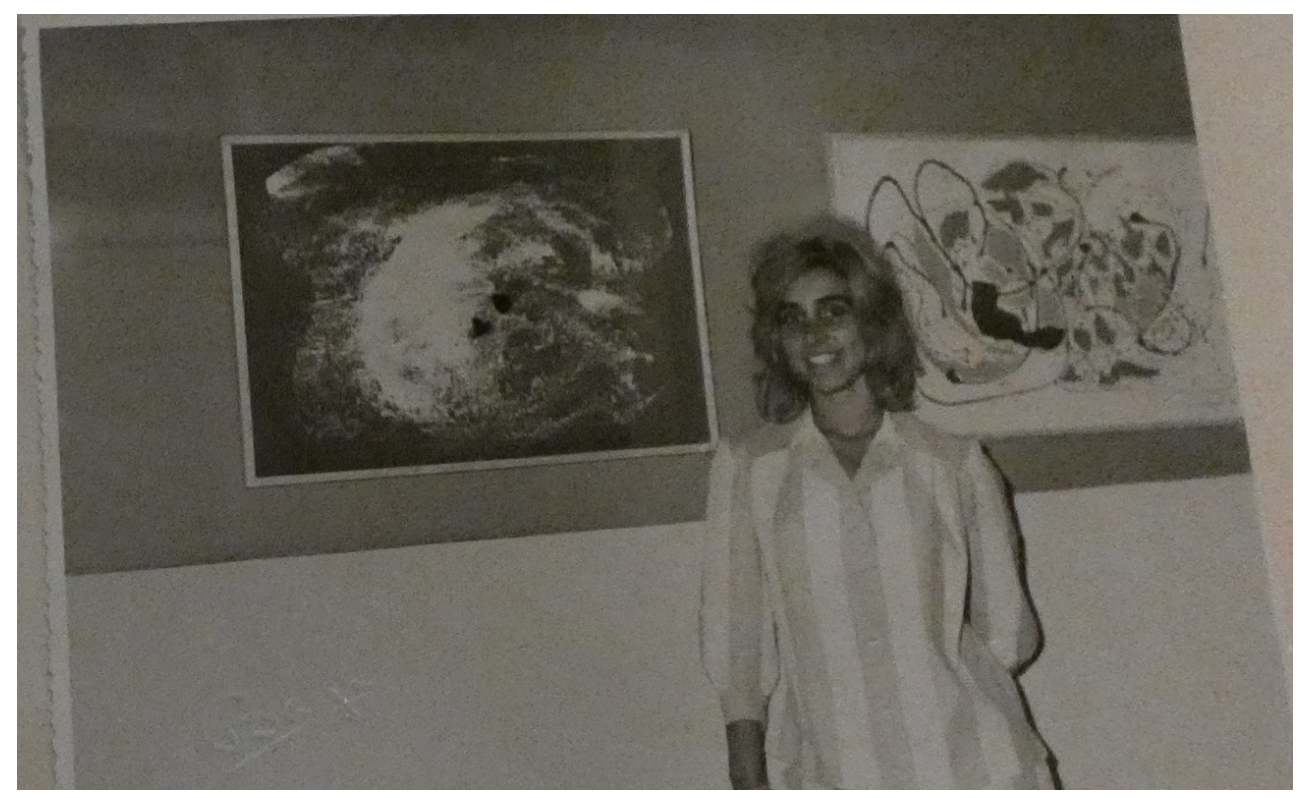

Fig. 5. Autor: Sin firma. Vivi Milano ante dos de sus cuadros, IEHC,1960. Archivos del IEHC, Puerto de La Cruz, Tenerife.

En 1961 no se reseña ninguna exposición femenina y sin embargo, el impulso feminista de Maud Bonneaud no cesa ${ }^{16}$. Además de las exposiciones en otros lugares, logra aglutinar a un grupo de artistas, que inicialmente exponen en el Círculo de Bellas Artes y en el Casino de Santa Cruz de Tenerife, dando lugar al grupo de Las Doce.

El IEHC es cada vez más hostil a la modernidad, pues podemos seguir la programación de sus actividades y comprobamos como cada vez resulta más difícil para los Westerdahl proponer exposiciones innovadoras. Sin embargo, en 1962, reseñamos dos exposiciones de mujeres artistas, la de Marina Barbado, que expone con Jorge 
Lindell del 16 al 30 de junio de 1962, y la de Maby Díaz, que expone del 22 al 30 de marzo de ese año.

Sin embargo, y pese a las dificultades, el último año de la influencia de los Westerdahl en el IEHC es 1965 y destacan entonces dos exposiciones: la de Viky Penfold, del 1 al 10 de febrero de ese año y, como cierre de una etapa, la colectiva Las Doce, del 18 al 28 de diciembre, y cuyo elenco es de una calidad extraordinaria: Birgitta Bergh, Quita Brodhead, Eva Fernández, Celia Ferreiro, Lola Massieu, Jane Millares, Ma Belén Morales, Viki Penfold, Carla Prina, Manon Ramos, Tanja Tamvelius y Maud Westerdahl.

María Belén Morales comentaba en 2015 rememorando la creación del grupo Las Doce y sus exposiciones:

Maud Westerdahl venía de París con ideas muy abiertas y nos sirvió de estímulo a las creadoras canarias que teníamos inquietudes. Las 12 marcó un punto de inflexión en la sociedad canaria. El objetivo era reclamar un espacio que nos correspondía, más allá del feminismo excluyente. Fue la primera vez que expusieron solo mujeres artistas ${ }^{17}$.

La exposición colectiva de Las Doce fue organizada por Maud Westerdahl y María Belén Morales, primero en el Círculo de Bellas Artes, donde estuvo abierta al público hasta el día cinco de diciembre. En la víspera, el día 4 de diciembre, el poeta Pedro García Cabrera había impartido una conferencia sobre Poesía Femenina. En el folleto de sala de la exposición que habían realizado en el Círculo de Bellas Artes, el texto es explícito:

Ni grupo, ni salón, ni colectiva, pues somos distintas. Exponemos juntas nada más. Coincidencias, simpatías mutuas y el común deseo de hacer algo. Tampoco carácter femenino. El solo hecho de ser mujeres no hubiera sido motivo suficiente para justificar la exposición. Nada de feminidad-labores-crochet. Nada tampoco de femenino-sufragista-reivindicación. Ninguna intención de tipo como los hombres o mejor que ellos, cosa que implicaría en sí una mezcla de agresividad... y admisión de su superioridad. Finalidad de la exposición: simplemente un acto. Declarar nuestra inquietud y seriedad artística y presentar nuestra busca y sus resultados ${ }^{18}$.

Una vez clausurada en el Círculo de Bellas Artes, la exposición fue trasladada al IEHC. Para el acto de inauguración el día 18 Maud Westerdahl y Maria Belén Morales contaron con Pilar Lojendio para un recital poético. Pese a sus intentos de dar el mismo tratamiento a la exposición en el IEHC, esta vez no pudieron imprimir un texto, sólo un tarjetón con un gran número 12 y los nombres de las artistas. La etapa de abierta modernidad en el IEHC había terminado. Sin embargo, en la memoria colectiva de Canarias esta exposición quedó como la muestra de una modernidad casi mítica, que sólo años más tarde sería reivindicada.

\footnotetext{
Morales, M.B.en Reyes, B. 12 Pioneras, Diario de Avisos, 19 de abril de 2015

Westerdahl, M. y Morales, M. B. (1965). Las Doce. Santa Cruz de Tenerife. Círculo de Bellas Artes. Folleto de sala.
} 


\section{Conclusiones}

En el mundo oscuro de posguerra, y en una ciudad alejada de las grandes capitales del momento, se vivió una etapa de extraordinaria modernidad gracias a la labor de Eduardo Westerdahl, ayudado desde 1955 por Maud Bonneaud. La importancia de las artistas que expusieron entonces es, desde la perspectiva actual, algo heterogénea, aunque sin duda la calidad de la obra es sobresaliente. A pesar de las dificultades de la época, en un país que estaba y estaría muchos años alejado de la modernidad, algunas ejercieron un papel importante dentro de la cultura en Canarias o fuera de las Islas.

En Tenerife debemos destacar el papel de Maud Bonneaud y de María Belén Morales, pues Las Doce no fue el final sino la culminación de un proceso. Su labor como animadora cultural y artista (Maud Bonneaud) y como artista y maestra de artistas (María Belén Morales), es esencial para entender la apertura cultural de Canarias.

En la provincia de Las Palmas, Pino Ojeda, Lola Massieu y Jane Millares fueron artistas y también maestras de otros artistas, los que las sitúa en paralelo a las dos iniciadoras de Las Doce. Las tres artistas grancanarias estuvieron estrechamente ligadas a la Escuela Luján Pérez, y tanto Pino Ojeda como Lola Massieu fueron fundadoras del Grupo Espacio años más tarde. En 1991 Lola Massieu recibió el Premio Canarias de Artes Plásticas e Interpretación.

La relación de estas artistas de Gran Canaria, además de Yolanda Graziani y Vivi Milano, con la revista Mujeres en la Isla es un dato a tener en cuenta, así como el hecho de que la singladura de la misma coincida prácticamente con los años de apertura del IEHC. La directora de la revista, María Teresa Prats de Laplace, fue quien entrevistó a Maud Bonneaud cuando expuso en Las Palmas, dato significativo de la fluidez de comunicación que había entre las Islas.

Algunas de las pintoras que citamos en el artículo, como Tanja Tamvelius y Vicky Penfold, especialmente la segunda, crearon a su alrededor centros de interés en Tenerife. Penfold abrió en su casa un taller para realizar estudios de desnudo, cosa que en aquella época era impensable en las escuelas oficiales.

La estrecha relación entre Maud Westerdahl, Valentine Penrose y Eileen Agar no decayó nunca, y tenemos prueba de ello en la correspondencia que mantuvieron durante toda su vida.

Visibilizar la importancia de estas mujeres artistas y trabajar para que ocupen su lugar en la Historia del Arte es la finalidad de este trabajo. Estamos en un momento esencial para cambiar la perspectiva de la Historia del Arte y dar a estas artistas el lugar que merecen en la historia. Confiamos en que este artículo hay cumplido su cometido. 